\title{
Short-term effects of a rights-based sexuality education curriculum for high-school students: a cluster-randomized trial
}

Norman A Constantine ${ }^{1,2^{*}}$, Petra Jerman ${ }^{1}$, Nancy F Berglas ${ }^{1}$, Francisca Angulo-Olaiz ${ }^{1}$, Chih-Ping Chou ${ }^{3}$ and Louise A Rohrbach ${ }^{3}$

\begin{abstract}
Background: An emerging model for sexuality education is the rights-based approach, which unifies discussions of sexuality, gender norms, and sexual rights to promote the healthy sexual development of adolescents. A rigorous evaluation of a rights-based intervention for a broad population of adolescents in the U.S. has not previously been published. This paper evaluates the immediate effects of the Sexuality Education Initiative (SEI) on hypothesized psychosocial determinants of sexual behavior.
\end{abstract}

Methods: A cluster-randomized trial was conducted with ninth-grade students at 10 high schools in Los Angeles. Classrooms at each school were randomized to receive either a rights-based curriculum or basic sex education (control) curriculum. Surveys were completed by 1,750 students ( $N=934$ intervention, $N=816$ control) at pretest and immediate posttest. Multilevel regression models examined the short-term effects of the intervention on nine psychosocial outcomes, which were hypothesized to be mediators of students' sexual behaviors.

Results: Compared with students who received the control curriculum, students receiving the rights-based curriculum demonstrated significantly greater knowledge about sexual health and sexual health services, more positive attitudes about sexual relationship rights, greater communication about sex and relationships with parents, and greater self-efficacy to manage risky situations at immediate posttest. There were no significant differences between the two groups for two outcomes, communication with sexual partners and intentions to use condoms.

Conclusions: Participation in the rights-based classroom curriculum resulted in positive, statistically significant effects on seven of nine psychosocial outcomes, relative to a basic sex education curriculum. Longer-term effects on students' sexual behaviors will be tested in subsequent analyses.

Trial registration: ClinicalTrials.gov NCT02009046.

Keywords: Adolescent, Sexuality education, Comprehensive sexuality education, Sexual behavior, Sexual rights, Gender norms, Intervention, Evaluation

\footnotetext{
* Correspondence: nconstantine@berkeley.edu

${ }^{1}$ Center for Research on Adolescent Health and Development, Public Health Institute, 555 12th Street, 10th Floor, 94607 Oakland, CA, USA

${ }^{2}$ Division of Community Health and Human Development, School of Public Health, University of California, Berkeley, 50 University Hall, 94720 Berkeley,

CA, USA

Full list of author information is available at the end of the article
}

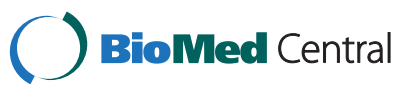

(c) 2015 Constantine et al.; licensee BioMed Central. This is an Open Access article distributed under the terms of the Creative Commons Attribution License (http://creativecommons.org/licenses/by/4.0), which permits unrestricted use, distribution, and reproduction in any medium, provided the original work is properly credited. The Creative Commons Public Domain Dedication waiver (http://creativecommons.org/publicdomain/zero/1.0/) applies to the data made available in this article, unless otherwise stated. 


\section{Background}

Despite sharp declines since its peak in the 1990s [1], the teen birth rate in the United States remains high relative to many other developed countries [2,3], and marked disparities persist by racial and ethnic group $[1,4]$. Moreover, rates of many sexually transmitted infections (STIs) are particularly high among adolescent and young adult populations, potentially causing longterm health problems and contributing to high health care costs for screening and treatment $[5,6]$. Recent decades have seen a range of efforts aimed at reducing rates of teen births and STIs, and more than $95 \%$ of U.S. adolescents now report having received some formal sexuality education in a school, church or community setting by age 18 [7]. The content and format of formal sexuality education interventions have varied greatly over time, with the current emphasis centered on school-based programs that provide instruction on abstinence from sexual activity plus the use of contraception and condoms for those who are sexually active [8-12].

Among adolescent sexual health scholars and advocates in the U.S. and globally, discussions around sexuality education are increasingly being framed more broadly-embracing comprehensive approaches based on frameworks of positive sexual health promotion and youth development and going beyond the typically more limited focus on pregnancy and disease prevention [12-15]. One emerging model is the rights-based approach, which seeks to unify issues of sexuality, human rights, and gender to promote healthy sexual development [16]. More specifically, the rights-based approach is guided by a recognition of adolescents' fundamental rights to sexual health information and services, selfdetermination, and non-discrimination, which also are core to frameworks of reproductive rights $[17,18]$ and reproductive justice [19]. It expands the goals of sexuality education beyond disease and pregnancy prevention to include positive sexuality, empowerment, and even civic engagement, and incorporates curriculum content related to the larger contextual issues that affect adolescents' sexual lives, including gender and cultural norms, relationship power, and sexual orientation.

Although a rights-based framework has been referenced in a number of international standards and guidelines [20-22] and some U.S. advocacy efforts [23], the development of programs that operationalize these concepts is still at a nascent stage, particularly in the United States. One resource has been the Population Council's 2009 It's All One kit of curriculum guidelines and activities [24], and documentation of its use in a variety of settings is underway [25]. There have been descriptive field reports of positive experiences from rights-based programs around the world [25-27]. In addition, research studies of conceptually related interventions (such as those that have incorporated discussions of gender norms) have been cited as evidence supporting the approach [28-33]. These more rigorous studies, which include randomized controlled trials and a meta-analysis, have found positive effects on sexual health outcomes, but may be limited in their applicability to adolescents in U.S. schools due to differences in country contexts, intervention settings, and/or target populations. For example, most have focused on young adult populations, and those studies that have centered on adolescents typically have been limited to sexually active females presenting in clinic settings. To our knowledge, no rigorous evaluation has been published of a rights-based sexuality education intervention for adolescents in the United States.

\section{The present study}

We conducted a cluster-randomized trial of a multicomponent, rights-based sexuality education intervention delivered to students enrolled in high schools in low-income, urban communities of Los Angeles. The primary aim of the trial was to determine the effectiveness of a new rights-based classroom curriculum. The secondary aim was to evaluate the impact of the multicomponent intervention, which included the curriculum as well as parent education workshops and materials, a peer advocate program, and access to sexual health services. In this article we examine the effects of the classroom curriculum, compared to a control curriculum, on shortterm psychosocial outcomes including sexual health knowledge, attitudes and communication. These shortterm psychosocial outcomes are expected to be mediators of longer-term effects on students' sexual behaviors, which will be tested in future analyses. We further examine differences in intervention effects by student gender and baseline sexual experience, two factors often considered as moderators of impact $[8,9]$. The secondary aim of the full study regarding the impact of the full multicomponent intervention will be addressed in a subsequent report based on the one-year follow-up data.

\section{The intervention}

The Sexuality Education Initiative (SEI) was developed by Planned Parenthood Los Angeles (PPLA) with the goal of improving the sexual and reproductive health of low-income, primarily Hispanic and African American youth in Los Angeles high schools. The SEI was designed to reach these goals by reducing students' risk of pregnancy and STIs, as well as improving students' ability to manage their sexuality respectfully. It employed a rights-based framework that focuses on human rights, gender equality, access to health care services, and critical thinking, and emphasized the relationship between broader social and cultural factors and individuals' sexual decisions. PPLA designed the SEI content and format on 
the basis of best practices outlined by international and U.S. organizations, as well as findings from formative research and pilot testing with the target community. A detailed overview of the influences, decisions, and processes related to program development is presented elsewhere [27].

The SEI was comprised of four components, one implemented at the classroom level and three implemented at the school level. At the classroom level, a 12-session rights-based curriculum for ninth-grade students addressed issues of gender roles and power dynamics in relationships and in media messages, and emphasized sexual rights, in addition to providing more commonly available content on sexual and reproductive anatomy, pregnancy, STIs/HIV, and contraception (see Table 1). The curriculum included the use of interactive techniques, such as small group exercises, classroom discussion, and critical thinking activities.

The three school-level SEI components included parent education workshops and materials, a peer advocate program, and access to sexual health services. Educational workshops for parents addressed adolescent sexuality, teen pregnancy, STIs, healthy relationships, values, and parent-teen communication. An after-school peer advocacy program offered intensive training and leadership skill-building for selected students, who in turn planned sexual health awareness events and publicized available health services on campus to their classmates. Sexual health services were made available through a "clinic without walls" model, in which PPLA staff visited the regularly throughout the year and provided confidential and youth-friendly services (e.g., pregnancy and STI testing, counseling, prescriptions for contraceptives, and referrals). PPLA staff also distributed packets of free condoms to students and provided training to school staff to become condom distributors on their school campus.

The conceptual framework (theory of change) guiding the SEI design is shown in Table 2. At the broadest level, the SEI was designed to affect psychosocial outcomes-students' sex- and sexuality-related knowledge, attitudes, communication, self-efficacy, and behavioral intentions-in the short-term and long-term, and sexual behaviors in the long-term. In the present paper, we focus on short-term outcomes, which are expected to be mediators of longer-term effects on sexual behaviors.

\section{Methods}

\section{Study design}

The study was conducted with ninth-grade students enrolled at 10 high schools in low-income, primarily Hispanic communities of Los Angeles. Ten charter schools affiliated with a local school district were selected and recruited to reflect the overall profile of students in the local communities while offering a smaller, contained environment in a charter school setting to conduct intervention research. School administrators agreed to the randomization of intervention components, delivery of the intervention, administration of the survey instrument, and restriction of similar programs on site for the duration of the study period. Following a one-year pilot test (2010-11) the intervention was delivered across two school-year cohorts. In Year 1 (2011-12), eight high schools participated in the study. Following the first year, one matched pair of schools dropped

\section{Table 1 Overview of Sexuality Education Initiative (SEI) 12-session classroom curriculum topics}

\begin{tabular}{|c|c|}
\hline Lesson & Topics \\
\hline 1. Introduction & Overview of program goals; introduction to gender stereotypes; availability of clinical sexual health services \\
\hline $\begin{array}{l}\text { 2. Social and media } \\
\text { messages }\end{array}$ & $\begin{array}{l}\text { Images of femininity, masculinity, sex, and sexuality in popular media; impact of media on body image and } \\
\text { gender-based violence }\end{array}$ \\
\hline 3. Gender and identity & Gender roles and stereotypes; how gender roles change over time; how strict gender roles can affect relationships \\
\hline 4. Relationships & Rights and responsibilities in sexual relationships; signs of healthy and unhealthy relationships \\
\hline 5. Sexuality & Defining sex and sexuality; sexuality as healthy and normal part of life; choosing abstinence and reasons to delay sex \\
\hline $\begin{array}{l}\text { 6. Sexual and reproductive } \\
\text { anatomy }\end{array}$ & $\begin{array}{l}\text { Male and female anatomy; understanding how bodies work and normal differences in bodies' shapes, sizes, and } \\
\text { colors }\end{array}$ \\
\hline 7. Pregnancy & Biology of conception and pregnancy; pregnancy options; reasons for becoming or not becoming a parent \\
\hline 8. STIs and safer sex & How STIs are transmitted; differences between curable and treatable STIs; practicing safer sex; condom demonstration \\
\hline 9. HIV/AIDS & HIV/AIDS transmission, prevention and testing; continuum of risk for sexual behaviors \\
\hline 10. Contraception & $\begin{array}{l}\text { Common methods of pregnancy prevention; effectiveness and safety of methods; how gender norms may affect } \\
\text { decisions about sex; partner communication }\end{array}$ \\
\hline $\begin{array}{l}\text { 11. Sexual choice and } \\
\text { coercion }\end{array}$ & $\begin{array}{l}\text { Unwanted vs. wanted sexual activity; consent; right to say 'no' and responsibility to ask; knowing one's sexual limits; } \\
\text { partner communication }\end{array}$ \\
\hline 12. Decision-making & $\begin{array}{l}\text { Making healthy decisions about sex and relationships; how gender stereotypes may affect decision-making; identifying } \\
\text { future goals }\end{array}$ \\
\hline
\end{tabular}


Table 2 Sexuality Education Initiative (SEI) conceptual framework (theory of change)

\begin{tabular}{|c|c|c|c|}
\hline Components & Short-term outcomes (Mediators) & Long-term outcomes & Goals \\
\hline $\begin{array}{l}\text { 1. Classroom } \\
\text { curriculum }\end{array}$ & $\begin{array}{l}\text { 1. Increase understanding that men and } \\
\text { women have equal rights regarding } \\
\text { sexual relationships and sexual and } \\
\text { reproductive health }\end{array}$ & $\begin{array}{l}\text { 1. Reduce pregnancy risk, the percentage of } \\
\text { youth who report engaging in vaginal sexual } \\
\text { intercourse but not using an effective method } \\
\text { of contraception during the previous three months }\end{array}$ & $\begin{array}{l}\text { 1. Improve the sexual and } \\
\text { reproductive health of youth } \\
\text { attending Los Angeles high } \\
\text { schools }\end{array}$ \\
\hline $\begin{array}{l}\text { 2. Parent } \\
\text { education } \\
\text { workshops }\end{array}$ & $\begin{array}{l}\text { 2. Increase communication about } \\
\text { relationships, rights, and sexuality } \\
\text { with parents, guardians, or other } \\
\text { trusted adults }\end{array}$ & $\begin{array}{l}\text { 2. Reduce STI risk, the percentage of youth who } \\
\text { report engaging in oral or vaginal sexual intercourse } \\
\text { but not using a condom during the previous three } \\
\text { months }\end{array}$ & $\begin{array}{l}\text { 2. Improve the ability of youth } \\
\text { attending Los Angeles high } \\
\text { schools to manage their sexuality } \\
\text { respectfully }\end{array}$ \\
\hline $\begin{array}{l}\text { 3. Peer } \\
\text { advocate } \\
\text { program }\end{array}$ & $\begin{array}{l}\text { 3. Increase communication about } \\
\text { relationships, rights, and sexuality } \\
\text { with partners }\end{array}$ & \multirow{6}{*}{$\begin{array}{l}\text { 3. Reduce number of sexual partners } \\
\text { 4. Increase use of sexual and reproductive health } \\
\text { services }\end{array}$} & \\
\hline \multirow{5}{*}{$\begin{array}{l}\text { 4. Access to } \\
\text { sexual } \\
\text { health } \\
\text { services }\end{array}$} & $\begin{array}{l}\text { 4. Increase knowledge about sex, } \\
\text { sexuality, and sexual risk protection }\end{array}$ & & \\
\hline & $\begin{array}{l}\text { 5. Increase self-efficacy to assert sexual } \\
\text { limits and to manage risky situations }\end{array}$ & & \\
\hline & $\begin{array}{l}\text { 6. Increase intentions to protect self } \\
\text { from sexual risk }\end{array}$ & & \\
\hline & $\begin{array}{l}\text { 7. Increase access to accurate } \\
\text { information about sexuality and } \\
\text { sexual health }\end{array}$ & & \\
\hline & $\begin{array}{l}\text { 8. Increase access to and awareness of } \\
\text { sexual and reproductive health } \\
\text { services }\end{array}$ & & \\
\hline
\end{tabular}

out of the study due to school administration changes and a new matched pair of schools with similar student characteristics was added for Year 2 (2012-13). Thus, ten schools participated in intervention delivery over the two-year period.

Schools were randomized within five pairs of schools matched on percentages of Hispanic and African-American students, and students receiving free lunches. Within each matched pair, one school was randomly assigned to receive all three school-wide SEI components (parent education, peer advocacy, and sexual health services) and the other to receive only the sexual health services schoolwide component. Within each school, ninth-grade classrooms were randomized to receive either the 12-session SEI curriculum described above, or a 3-session control curriculum covering basic sexual health topics, including anatomy and prevention of unintended pregnancy and STIs. The control curriculum had been widely implemented by PPLA in previous years and reflected the "standard of care" for sexuality education in local high schools. Both SEI and control curriculum sessions were developed to fit into 50-minute class periods. The SEI sessions were administered across an average span of 53 days, and the control sessions across an average span of 9 days. The SEI curriculum was taught by PPLA staff who participated in a 2-day training on the rights-based curriculum; the control curriculum was taught by PPLA volunteer educators who participated in a 1-day training on the basic curriculum. Regular classroom teachers were present at all sessions.

\section{Ethical clearance}

The study was conducted in compliance with the institutional review boards of the University of Southern California and the Public Health Institute. Positive parental informed consent and student assent were required prior to students' participation in the evaluation.

\section{Data collection procedures}

Students whose parents provided consent and who assented to participate were administered a written survey at baseline (pretest), immediately following curriculum implementation (posttest), and at one-year following curriculum completion (follow-up). Surveys were administered and collected by study staff at single classroom sessions during regular school hours. Posttest surveys were administered within two weeks of the final session for both curricula. Students absent on testing days were left absentee packets, and asked by school staff to complete the survey in a private area of the classroom, place it a sealed envelope, and return it to the teacher for transmittal to evaluation staff.

To examine fidelity of program implementation, trained members of the research team conducted formal observations of intervention and control curriculum sessions. Across the two-year study period, 220 intervention sessions and 43 control sessions were observed (equivalent to $50 \%$ of all sessions in Year 1, and $25 \%$ of all sessions in Year 2), with coverage across all schools and sessions. Additionally, student attendance was tracked by PPLA or school staff at all sessions. 


\section{Participants}

Figure 1 displays the flow of participants in the present study, which focused on baseline pretest and immediate posttest surveys. Of 2,379 eligible students in the 91 classrooms at the 10 participating schools, 2,033 (85.5\%) consented to participate. Consent rates were similar for intervention (85.9\%) and control (84.9\%) students. At pretest, $5.7 \%$ of cases $(5.9 \%$ in control group and $5.4 \%$ in intervention group) were excluded due to the student's absence or invalid survey (e.g., blank or mostly blank). In addition, $0.5 \%$ of the remaining cases $(0.5 \%$ in control group and $0.5 \%$ in intervention group) were excluded due to invalid data (e.g., multiple inconsistencies across responses). At the immediate posttest, $6.0 \%$ of cases were lost due to attrition (5.8\% in control curriculum group and $6.2 \%$ in SEI curriculum group). In addition, at the immediate posttest, $2.5 \%$ of the remaining cases were excluded due to invalid data $(2.0 \%$ in control group and $2.8 \%$ in intervention group). The final pretestimmediate posttest merged dataset included a total of 1,750 students, with 934 students in 48 SEI curriculum classrooms and 816 students in 43 control classrooms.

\section{Measures}

\section{Survey development}

The student survey was developed following a multistep process. Items were identified in the research literature and reviewed for appropriateness for the target population and intervention objectives. New measurement scales of rights- and gender-based constructs were developed based on formative research with youth and parents [34] and a comprehensive review of the developing classroom curriculum. One-on-one cognitive interviews were conducted with youth to assess comprehension of the items and evaluate the quality of responses, after which the survey was revised accordingly. A pilot version of the survey was administered to more than 700 ninth-grade students at six high schools in the target communities in the year prior to program implementation. Psychometric analyses of reliability and validity were conducted based on these responses, leading to further revisions to the survey items and scales. Additionally, the pilot testing revealed that some students could not complete the entire survey during the available 50-minute class period. To address this challenge we reduced the survey length and student burden by creating two parallel shorter survey forms, with each form randomly administered to half the students in the sample. As a result, a small number of items and scales (described below) appeared on only one of the two survey forms.

\section{Psychosocial outcomes}

The following survey measures were used to assess the nine short-term psychosocial outcomes (mediators) that were established in the framework guiding the SEI design.

Attitudes about rights in sexual relationships Two 17-item scales assessed attitudes about one's sexual relationship rights with a steady partner, or with a casual

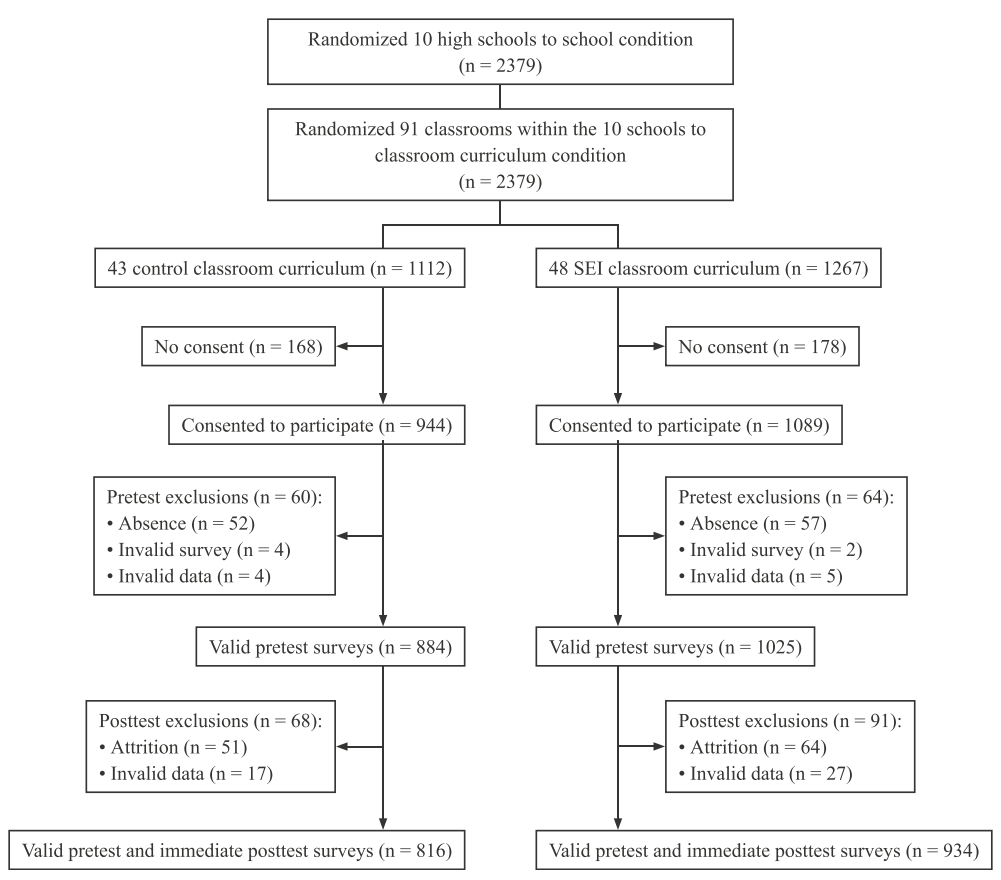

Figure 1 Participant flow from randomization to final analysis sample. 
partner (e.g., "With [a steady partner (like a boyfriend or a girlfriend)/someone I just met], a person always has the right to stop having sex with their partner at any time."). For each scale, the items were averaged, and the coefficient alphas were .89 and .90 , respectively. Each set of items was included on one version of the survey and, therefore, was answered by a random half of the sample. For each item, students indicated their agreement on a 4-point Likert-type scale (strongly disagree to strongly agree). A higher mean score indicated more-positive attitudes about one's rights in sexual relationships.

Communication about relationships, rights, and sexuality with partners Sexual communication with one's current or most recent steady partner was measured by a 9-item scale (e.g., "Did you ever talk with your current or recent steady partner about whether or not to have sex?"). The items were summed, creating a total score that ranged from 0 to 9 , with a higher score indicting a greater number of topics discussed.

Communication about relationships, rights, and sexuality with parents/guardians Sexual communication with one's parent or guardian was measured by a 15item scale (e.g., "Have you ever talked with your parent or guardian about oral sex?"). The items were summed, creating a total score that ranged from 0 to 15 , with a higher score indicating a greater number of topics discussed. The scale items were included on only one version of the survey and, therefore, were answered by a random half of the sample.

Knowledge about sex, sexual health, and sexual risk protection Sexual health knowledge was assessed using 17 items (e.g., "If a condom is used correctly, it helps protect against HIV."). For each item, students indicated whether they believed the statement to be true or not true. The items were summed, creating a total score that ranged from 0 to 17 , with a higher score indicting a greater number of correct items.

Self-efficacy to assert sexual limits and manage risky situations Students' protection self-efficacy was measured by a 6-item scale (e.g., "I know how to say 'no' to sex."). The items were averaged, and the coefficient alpha was .78. For each item, students indicated their agreement on a 4-point Likert-type scale. A higher mean score indicated higher self-efficacy.

Intentions to protect oneself from sexual risk through condom use Students' intentions to use condoms with a sexual partner were measured by a 3-item scale (e.g., "If I had sex with someone, we would use a condom."). The items were averaged, and the coefficient alpha was .84 .
For each item, students indicated their agreement on a 4-point Likert-type scale. A higher mean score indicated a greater level of condom-use intentions.

Access to accurate information about sexuality and sexual health A single item assessed whether students knew of a person or place where they could access good information about sexuality or sexual health. For these analyses, responses were dichotomized as "yes" or "no/ not sure".

Awareness of sexual and reproductive health services A single item assessed whether students knew where they could access sexual health services (defined as birth control, pregnancy tests, and STI tests). For these analyses, responses were dichotomized as "yes" or "no/not sure".

\section{Student characteristics}

Additional survey items assessed student demographic and behavioral characteristics at baseline. Gender was measured dichotomously. Household crowding was used as a proxy for socioeconomic status, and was measured as the ratio of the number of rooms in the student's home by the number of people living in the home [35]. Acculturation was measured using an adapted version of a brief scale developed by Marin and colleagues [36] and validated with Hispanic adolescents [37]; we calculated a mean score across four items that assessed the extent to which the student relied on English or another language when reading, speaking with friends, watching movies or television, and speaking at home $[36,37]$. Responses were measured on a 5-point scale ranging from "only English" (1) to "only another language (besides English)" (5); for data analyses, the responses were reverse coded. Students were also asked whether they were born in the United States. Sexual experience was measured dichotomously; students were asked if they ever had sex, with sex defined as vaginal or anal sex. Students' age and race/ethnicity were collected, but not used in these analyses due to limited variation in responses.

\section{Fidelity of implementation}

This paper presents three measures of fidelity of implementation: 1) student attendance (tracked by project staff), 2) delivery of all sections and activities in a session according to the lesson plan (based on observations), and 3) delivery of session content according to the lesson plan (based on observations). Attendance data were summarized as the mean percentage of students in attendance at each session in a given classroom. Completion of session sections and activities by the educator was assessed by trained members of the research team during formal classroom observations and summarized as the percentage 
of sections and activities delivered. Delivery of session content according to the lesson plan was assessed during classroom observations and measured on a scale of 1 ("not at all closely") to 5 ("very closely").

\section{Analyses}

Attrition analyses were conducted to determine whether the attrition rate was comparable across curriculum intervention groups and to examine whether students who were lost to follow-up differed on key characteristics from those who were retained. Students' demographic and baseline behavioral characteristics were compared between the two curriculum intervention groups.

Comparisons of pretest-posttest changes in outcome measures by curriculum intervention group were conducted using multilevel linear and logistic regression models (using SAS 9.2 PROC MIXED and GLIMMIX procedures) to account for the interdependence among clustered student observations due to classroom and school affiliations [38-40]. Statistical significance levels of $\mathrm{p}<.05$ were employed across all analyses. The shortterm outcomes tested were posttest scores on the nine short-term psychosocial measures described above. To account for interdependence at the school level (10 schools), a school identification variable was entered as a fixed effect. To account for interdependence at the classroom level (91 classrooms), a classroom identification variable was entered as a random effect. Classroom curriculum intervention group (control vs. SEI) was included as a fixed effect. Student level covariates included gender, household SES, acculturation, baseline sexual experience, and the pretest measure of the tested outcome. The two continuous covariates-household SES and acculturation-were group-mean centered (i.e., centered on the variable's classroom mean).

We examined two cross-level interactions for all nine short-term outcomes to examine differential intervention effect by gender and sexual experience. The first interaction was between curriculum intervention group and student gender (individual-level), and the second one between curriculum intervention group and student baseline sexual experience (individual-level). Furthermore, classroom mean gender and classroom mean baseline sexual experience were included in the models as classroom-level covariates to reflect the environmental influence of the classroom (contextual effects); both were centered by subtracting a constant (i.e., the mean across all the classroom means) from each classroom's mean. As part of examining these contextual effects, we also added two classroomlevel interactions to the models. The first interaction was between curriculum intervention group and classroom mean gender, and the second one between curriculum intervention group and classroom mean sexual experience. As variables were added to the regression models, we tested model fit by examining statistically significant differences in model deviance. When a subsequent model did not show an improved fit over a previous model, the previous model was chosen as the final model for interpreting results.

For the seven continuous outcomes, effect sizes were represented by adjusted standardized mean differences, which were calculated by dividing the regression estimate by the within-classroom standard deviation for the final model. The within-classroom standard deviation was used rather than the between-classroom standard deviation because the latter was either zero or near zero in the final models. For the two dichotomous outcomes, effect sizes were represented by odds ratios.

\section{Results}

\section{Attrition}

Comparisons between students lost to attrition and students who were retained were made on seven key background characteristics assessed at pretest (see Table 3). The comparisons revealed that students who were lost to attrition were more likely to be older, non-Hispanic,

Table 3 Comparison of students retained for analysis with students lost to attrition at posttest

\begin{tabular}{|c|c|c|c|}
\hline Variable & $\begin{array}{l}\text { Retained } \\
\text { students }\end{array}$ & $\begin{array}{l}\text { Lost to } \\
\text { attrition }\end{array}$ & $p$ value \\
\hline Overall (\%) & $(N=1794)$ & $(\mathrm{N}=115)$ & \\
\hline Control & 94.2 & 5.8 & \\
\hline SEl & 93.8 & 6.2 & 0.664 \\
\hline Gender (\%) & $(N=1786)$ & $(\mathrm{N}=108)$ & \\
\hline Male & 49.5 & 47.2 & \\
\hline Female & 50.5 & 52.8 & 0.646 \\
\hline Age (12-18 years) & $(N=1745)$ & $(\mathrm{N}=108)$ & \\
\hline Mean (SD) & $14.21(0.60)$ & $14.38(0.77)$ & 0.026 \\
\hline Hispanic (\%) & $(N=1690)$ & $(\mathrm{N}=101)$ & \\
\hline No & 9.2 & 15.8 & \\
\hline Yes & 90.8 & 84.2 & 0.027 \\
\hline Born in the United States (\%) & $(\mathrm{N}=1696)$ & $(\mathrm{N}=104)$ & \\
\hline No & 14.2 & 9.6 & \\
\hline Yes & 85.8 & 90.4 & 0.189 \\
\hline Household SES (0-3) & $(\mathrm{N}=1710)$ & $(N=104)$ & \\
\hline Mean (SD) & $0.57(0.28)$ & $0.63(0.27)$ & 0.043 \\
\hline Student acculturation (1-5) & $(N=1726)$ & $(N=105)$ & \\
\hline Mean (SD) & $3.81(0.71)$ & $3.95(0.76)$ & 0.051 \\
\hline Ever had sex $\neq(\%)$ & $(N=1770)$ & $(N=112)$ & \\
\hline No & 79.2 & 53.6 & \\
\hline Yes & 20.8 & 46.4 & 0.000 \\
\hline
\end{tabular}

\#Defined as vaginal or anal sex. Notes: Difference between groups was tested by chi-square for categorical variables and $t$ test for continuous variables, at $p<.05$. The analyses were not adjusted for interdependence due to classroom and school affiliations. 
from a higher household SES, and more likely to have ever had sex at pretest than were students who were retained $(\mathrm{p}<.05)$. There were no statistically significant differences by gender or by being born in the U.S. The difference in rate of attrition from pretest to immediate posttest for the control curriculum group (5.8\%) relative to the SEI curriculum group (6.2\%) was not statistically significant.

\section{Baseline characteristics}

Baseline characteristics of students by curriculum intervention group are presented in Table 4. Overall, the SEI curriculum group and the control curriculum group were similar across baseline characteristics, with no statistically significant differences observed. Fifty-one percent of the students in the total sample were female, and the mean student age was 14.20 years. In addition, $85.9 \%$ of students identified as Hispanic, and $81.1 \%$ were born in the United States. Students in the total sample had a mean household SES of 0.57 on a scale of 0 to 3, and a mean acculturation score of 3.81 on a scale of 1 to 5 .

Table 4 Baseline characteristics of students by curriculum intervention group

\begin{tabular}{llll}
\hline Characteristic & $\begin{array}{l}\text { Total } \\
(\mathbf{N}=\mathbf{1 7 5 0})\end{array}$ & $\begin{array}{l}\text { Control } \\
\mathbf{( N = 8 1 6 )}\end{array}$ & $\begin{array}{l}\text { SEI } \\
\mathbf{( N = 9 3 4 )}\end{array}$ \\
\hline Gender (\%) & & & \\
Male & 49.1 & 48.8 & 49.4 \\
Female & 50.6 & 50.7 & 50.5 \\
Missing & 0.3 & 0.5 & 0.1 \\
Age (12-18 years), mean (SD) & $14.20(0.60)$ & $14.19(0.58)$ & $14.22(0.62)$ \\
Hispanic (\%) & & & \\
No & 8.6 & 8.5 & 8.7 \\
Yes & 85.9 & 85.0 & 86.7 \\
Missing & 5.5 & 6.5 & 95.4 \\
Born in the United States (\%) & & & \\
No & 13.5 & 13.2 & 13.7 \\
Yes & 81.1 & 80.6 & 81.6 \\
Missing & 5.4 & 6.1 & 4.7 \\
Household SES (0-3), & $0.57(0.27)$ & $0.57(0.26)$ & $0.57(0.27)$ \\
mean (SD) & & & \\
Student acculturation (1-5), & $3.81(0.70)$ & $3.81(0.70)$ & $3.81(0.71)$ \\
mean (SD) & & & \\
Ever had sex¥ (\%) & & 80.1 & 79.1 \\
No & 79.6 & 18.5 & 19.5 \\
Yes & 19.0 & 1.3 & 1.4 \\
Missing & 1.4 & & \\
\hline
\end{tabular}

\#Defined as vaginal or anal sex. Notes: Percentages might not add up to $100 \%$ due to rounding. Differences between control and intervention classrooms were tested by chi-square for categorical variables and $t$ test for continuous variables, at $\mathrm{p}<.05$. The analyses were not adjusted for interdependence due to classroom and school affiliations.
Nearly one-fifth (19.0\%) reported having had vaginal or anal sex in their lifetime.

\section{Overall outcomes}

Students' unadjusted pretest and immediate posttest outcome measure scores in both curriculum intervention groups are shown in Table 5. The adjusted pretestposttest score differences between the two groups were examined in multilevel linear and logistic regression models. Table 5 shows the results of the final regression model for each outcome.

Results indicated that students in the SEI curriculum group showed larger increases in scores from pretest to posttest than students in the control curriculum group, and that this SEI curriculum group effect was statistically significant for seven of the nine outcome measures. The largest curriculum intervention group effects were found for the scales assessing sexual health knowledge (adjusted standardized mean difference $=0.44$ ), attitudes about rights in sexual relationships with a casual partner (0.42), and self-efficacy to assert sexual limits and manage risky situations (0.37). For the dichotomous outcomes, the odds of students in the SEI curriculum group having access to information about sexuality and sexual health and being aware of sexual and reproductive health services were 2.61 and 2.48 times larger, respectively, than the odds of students in the control group.

\section{Effects by gender and baseline sexual experience}

In examining interactions of curriculum intervention group by student gender and baseline sexual experience for each outcome, we found no statistically significant differential effects (see Table 6). Although student gender had a statistically significant main effect on most of the outcome measures (results not shown), this did not translate into differential effects by curriculum intervention group.

To examine the contextual influence of the classroom, we also included in the models classroom-level measures of these two covariates-classroom mean gender and classroom mean sexual experience-as well as their interactions with curriculum intervention group. We found no statistically significant contextual effect of classroom mean gender for any of the outcomes and no statistically significant interaction effect with curriculum intervention group. We also found no statistically significant contextual effect of classroom mean sexual experience for any of the outcomes, and only one statistically significant interaction effect with the curriculum intervention group. For the final model examining attitudes about rights in sexual relationships with a casual partner, the results indicated a non-significant main contextual effect 
Table 5 Unadjusted and adjusted outcome measures by curriculum intervention group for nine short-term psychosocial outcomes

\begin{tabular}{|c|c|c|c|c|c|c|c|}
\hline \multirow{3}{*}{$\begin{array}{l}\text { Outcome measure } \\
\text { Continuous measures }\end{array}$} & \multicolumn{2}{|l|}{ Control } & \multicolumn{2}{|l|}{ SEI } & \multirow{2}{*}{\multicolumn{2}{|c|}{$\begin{array}{l}\text { Multilevel regression estimates and effect } \\
\text { sizes }\end{array}$}} & \multirow[t]{3}{*}{$\mathrm{ICC}$} \\
\hline & \multirow[t]{2}{*}{ Pretest } & \multirow[t]{2}{*}{ Posttest } & \multirow[t]{2}{*}{ Pretest } & \multirow[t]{2}{*}{ Posttest } & & & \\
\hline & & & & & Estimate $(\mathrm{Cl})$ & $\begin{array}{l}\text { Adjusted standardized } \\
\text { mean difference }(\mathrm{Cl})\end{array}$ & \\
\hline $\begin{array}{l}\text { Rights with steady partner (1-4), } \\
\text { mean (SD), } N=783\end{array}$ & $3.25(0.41)$ & $3.29(0.51)$ & $3.21(0.41)$ & $3.38(0.50)$ & $0.12(0.06-0.18)^{* *}$ & $0.29(0.15-0.44)$ & 0.000 \\
\hline $\begin{array}{l}\text { Rights with casual partner }(1-4) \text {, } \\
\text { mean (SD), } N=753\end{array}$ & $3.11(0.49)$ & $3.14(0.57)$ & $3.13(0.46)$ & $3.30(0.52)$ & $0.19(0.11-0.27)^{* *}$ & $0.42(0.25-0.59)$ & 0.031 \\
\hline $\begin{array}{l}\text { Communication with partners (0-9), } \\
\text { mean (SD) } N=1134\end{array}$ & $2.81(2.54)$ & $3.24(2.92)$ & $3.16(2.75)$ & $3.62(3.00)$ & $0.14(-0.13-0.40)$ & $0.06(-0.06-0.18)$ & 0.000 \\
\hline $\begin{array}{l}\text { Communication with parents }(0-15) \text {, } \\
\text { mean }(S D), N=1624\end{array}$ & $5.68(4.54)$ & $6.01(4.99)$ & $5.96(4.75)$ & $6.70(5.25)$ & $0.51(0.10-0.92)^{*}$ & $0.13(0.03-0.23)$ & 0.000 \\
\hline $\begin{array}{l}\text { Sexual health knowledge }(1-17) \text {, } \\
\text { mean (SD), } N=1675\end{array}$ & $10.90(2.29)$ & $12.63(2.16)$ & $10.67(2.31)$ & $13.40(2.17)$ & $0.88(0.65-1.12)^{* *}$ & $0.44(0.33-0.56)$ & 0.031 \\
\hline $\begin{array}{l}\text { Self-efficacy to assert oneself }(1-4) \text {, } \\
\text { mean (SD), } N=1545\end{array}$ & $2.91(0.56)$ & $3.16(0.50)$ & $2.93(0.58)$ & $3.33(0.52)$ & $0.17(0.12-0.22)^{* *}$ & $0.37(0.26-0.47)$ & 0.000 \\
\hline $\begin{array}{l}\text { Intentions to protect oneself }(1-4) \text {, } \\
\text { mean (SD), } N=1584\end{array}$ & $3.42(0.63)$ & $3.43(0.65)$ & $3.44(0.60)$ & $3.46(0.65)$ & $0.03(-0.03-0.09)$ & $0.05(-0.05-0.15)$ & 0.008 \\
\hline Dichotomous measures & & & & & Logit estimate $(\mathrm{Cl})$ & Odds ratio $(\mathrm{Cl})$ & \\
\hline $\begin{array}{l}\text { Access to sexual health information (yes), } \\
\%, N=1685\end{array}$ & $44.1 \%$ & $73.2 \%$ & $46.1 \%$ & $86.7 \%$ & $0.96(0.68-1.24)^{* *}$ & $2.61(1.97-3.47)$ & 0.012 \\
\hline $\begin{array}{l}\text { Awareness of sexual health services (yes), } \\
\%, N=1693\end{array}$ & $49.5 \%$ & $75.1 \%$ & $49.6 \%$ & $87.0 \%$ & $0.91(0.62-1.20)^{* *}$ & $2.48(1.85-3.31)$ & 0.009 \\
\hline
\end{tabular}

${ }^{*} \mathrm{p}<.05 .{ }^{* *} \mathrm{p}<.001 . \mathrm{ICC}=$ intraclass correlation coefficient. $\mathrm{Cl}=$ confidence interval. Notes: Final models were adjusted for student gender, classroom mean gender, student sexual experience, classroom mean sexual experience, and pretest score. The adjusted standardized mean difference represents the regression estimate divided by the within-classroom standard deviation from the final model for each outcome; the confidence interval for the adjusted standardized mean difference represents the regression estimate's confidence interval divided by the within-classroom standard deviation from the final model for each outcome.

of classroom mean sexual experience (results not shown). But, the statistically significant interaction $(p<.05)$ with curriculum intervention group showed that the influence of sexual experience was greatly reduced in the SEI curriculum group, relative to the control curriculum group (results not shown).

\section{Fidelity of implementation}

Average student attendance across classrooms was $90.4 \%$ for the intervention curriculum and $90.3 \%$ for the control curriculum. Most lessons and activities were delivered in their entirety for both the intervention (97.7\%) and control (96.0\%) classrooms. Mean scores for educator delivery

Table 6 Multilevel regression estimates (confidence intervals) for interactions between curriculum intervention group and gender and baseline sexual experience

\begin{tabular}{lll}
\hline Outcome measure & \multicolumn{1}{c}{ Interaction between curriculum intervention group and } & Student baseline sexual experience \\
\cline { 2 - 3 } & Student gender & $0.04(-0.11-0.19)$ \\
\hline Rights with steady partner $(\mathrm{N}=783)$ & $-0.02(-0.14-0.09)$ & $-0.12(-0.29-0.06)$ \\
Rights with casual partner $(\mathrm{N}=753)$ & $-0.02(-0.16-0.11)$ & $0.10(-0.53-0.72)$ \\
Communication with partners $(\mathrm{N}=1134)$ & $0.05(-0.48-0.58)$ & $-0.60(-1.41-0.22)$ \\
Communication with parents $(\mathrm{N}=1624)$ & $-0.09(-0.48-0.31)$ & $0.21(-0.30-0.73)$ \\
Sexual health knowledge $(\mathrm{N}=1675)$ & $0.09(-0.00-0.19)$ & $0.05(-0.08-0.17)$ \\
Self-efficacy to assert oneself $(\mathrm{N}=1545)$ & $0.02(-0.10-0.13)$ & $-0.01(-0.16-0.15)$ \\
Intentions to protect oneself $(\mathrm{N}=1584)$ & $0.31(-0.24-0.86)$ & $0.23(-0.50-0.97)$ \\
Access to sexual health information (yes; $\mathrm{N}=1685)$ & $-0.05(-0.59-0.50)$ & $0.24(-0.51-0.98)$ \\
Awareness of sexual health services (yes; $\mathrm{N}=1693)$ &
\end{tabular}

Notes: None of the interactions was statistically significant. Models were adjusted for curriculum intervention group, student gender, classroom mean gender, student sexual experience, classroom mean sexual experience, and pretest score. 
of content according to the lesson plan were 4.52 and 4.39 (on a scale from 1 to 5) for the intervention and control classrooms, respectively.

\section{Discussion}

The results indicate a largely consistent pattern of shortterm intervention effects of a new rights-based sexuality education curriculum on ninth-grade students' knowledge, attitudes, communication, and self-efficacy about sex and sexuality. Students' scores increased from pretest to posttest for all nine of the short-term outcome measures outlined in the conceptual framework guiding the SEI design. For seven of these outcomes, students who received the SEI's rights-based classroom curriculum showed statistically significantly greater improvements than did students who received a basic sex education (control) curriculum.

The magnitude of these effects offers additional support to these results. The effect size, as measured by the adjusted standardized mean difference, for four of the five statistically significant continuous outcomes exceeded 0.20 , the level considered of policy relevance in educational research $[41,42]$. In addition, findings for the two dichotomous measures indicated that the odds of SEI curriculum students reporting access to sexual health information and awareness of sexual health services were more than twice as large as for the control curriculum students.

The absence of intervention effects for two of the shortterm outcomes might be explained in part by issues of measurement, and in part by the content of each curriculum. Although the control curriculum did not address partner communication as explicitly as the SEI curriculum, it is possible that even basic classroom discussions of reproductive anatomy, pregnancy, contraceptive methods, and STI prevention might raise awareness of the importance of communicating with one's partner about sexual decision-making. More sensitive measures of frequency and quality of partner communication might lead to the detection of posttest differences between curriculum groups, if they exist. The null intervention effect on students' intentions to use condoms might be indicative of a ceiling effect in the survey measure. Scores were high for both the intervention and control groups at pretest (3.44 and 3.42, respectively, on a scale of 1 to 4), offering little opportunity for increase due to curriculum participation. In addition, our measure of condom use intentions was comprised of three survey items. The inclusion of more items might broaden the distribution of scores. For both cases of null intervention effects, improvement of survey measures in future research might clarify whether the absence of a statistically significant effect was due to limitations in measurement or the need for greater differentiation between the SEI and a control curriculum.
Notably, the effects of the SEI intervention on shortterm outcomes were consistent regardless of student gender or baseline sexual experience, two characteristics often considered as potential moderators of impact in sexuality education interventions. We found no evidence of differential intervention effects in this study. The finding that the SEI had similar short-term outcome effects on both male and female students is important, as this is one of the few rights-based sexual health interventions to address both male and female youth with a common curriculum. The absence of differential intervention effects by gender may reflect, at least in part, the overall intervention approach, which focuses on engaging all students together in discussions of gender, rights, and sexuality. It is also consistent with meta-analyses of adolescent pregnancy prevention interventions that have found no overall differences in impact on behavioral outcomes by gender for pooled estimates [43-45]. Similarly, the lack of differential effect by baseline sexual experience may reflect the deliberate design of the intervention for a broad population of adolescents. The SEI classroom curriculum sought to engage students whether or not they had yet become sexually active. It is important to note, however, that the small percentage of students who were sexually experienced at baseline, fewer than one in five, limits the statistical power of tests of differential effectiveness.

Our analyses further aimed to take into account the effect of the classroom environment by including classroom level variables for gender and sexual experience. We found no contextual effect by either variable. That is, there were no additional changes to the outcome scores due to the proportion of students in each class who were female or sexually experienced.

\section{Implications for research and practice}

This study offers a first look at the effectiveness of a rights-based sexuality education intervention for adolescents in U.S. schools and, as such, contributes to a greater understanding of this approach for those involved in sexuality education. Our findings are consistent with the small body of existing studies of interventions that have addressed similar concepts. For example, a quasiexperimental study of The World Starts with Me, a sexuality education program in secondary schools in Uganda emphasizing personal decision-making, social influences, gender equity, sexuality and rights, found a positive short-term impact on participating students' beliefs about pregnancy prevention, norms about delaying sex, and self-efficacy about condom use relative to a comparison group of students [33]. A series of clinic-based sexual health interventions developed by DiClemente and colleagues have emphasized issues of gender, empowerment and healthy relationships, with evidence supporting their 
impact on both psychosocial mediators and behavioral outcomes for sexually active African American adolescent girls [30,46]. A similar intervention for Hispanic adolescent girls is under development [47]. The preliminary findings from the present SEI evaluation trial lend further support to the potential of rights-based approaches.

These findings also lend support to the existing conceptual definitions and theoretical frameworks guiding the development of rights-based sexuality education. The connections between individuals' conceptions of gender and power in relationships and their sexual attitudes, behaviors, and health outcomes have been identified through prior research $[28,48-50]$, and mechanisms for the influence of cultural and societal expectations about gender on decisions about relationships and sexual behaviors have been proposed [50-52]. In this study, we offer further support to these conclusions by showing that exposure to a rights-based curriculum can positively affect young people's sexual knowledge, attitudes, and communication immediately following participation.

Finally, this study also brings attention to important issues of measurement and evaluation for sexuality education researchers. In 2012, the International Planned Parenthood Federation described the need to develop new measures of effectiveness for comprehensive sexuality education to balance broader outcomes, such as those related to gender and rights, with those related to public health [53]. Few such measures currently exist, especially for a school-based adolescent population in the U. S. For this trial, we developed and validated several new measures-such as attitudes about sexual relationship rights-that will enable future testing of hypothesized relationships between changes in knowledge, attitudes, and communication about gender, rights, and sexuality and changes in long-term sexual health outcomes.

\section{Strengths and limitations}

This study has a number of strengths that support our interpretation of its results. These include the randomization of classroom- and school-level clusters to treatment conditions, the use of a standard control curriculum to mirror the typical provision of sexuality education to high school students, the validation of survey measures through pilot testing and psychometric analyses, sound fidelity of implementation, the strong follow-up rates without indication of differential attrition between the intervention and control groups, and the use of multilevel analytic models to account for the clustered design. In addition, the randomized evaluation trial was enhanced by rigorous formative research methods and the use of existing best practices to both develop the curriculum and assess the fidelity of its implementation $[27,34]$.

These results should be considered in light of several limitations. First, the different lengths of the intervention and control curricula limit our ability to state conclusively that the SEI's rights-based approach was responsible for the positive pattern of results. Given the study design, it not possible to disentangle the effects of curriculum length from content through statistical analyses. We believe that the SEI's conceptual framework offers a strong explanation for the identified effects; nonetheless, it will be important for future research to examine this issue more closely. Second, as is common practice in school-based intervention studies, data were collected using self-report questionnaires which might be subject to response bias. Considerable efforts were made to support the validity and reliability of the survey measures, including the use of cognitive interviews during survey development to assess students' comprehension and response processes [54], the inclusion of measures to examine students' self-reported understanding, honesty, and carefulness in answering questions [55], and protocols to create a confidential environment during data collection. Third, for the three scales randomly administered to only half of the sample (sexual relationship rights with steady partner, sexual relationship rights with casual partner, and parent sexual communication), the effective sample size was half of what it was for the other scales, thereby reducing these scales' statistical power to capture real effects. Yet, because these three scales all yielded statistically significant intervention effects, this concern was eliminated. Finally, these findings might not be generalizable to populations beyond the sample of urban, low-income, predominantly Hispanic high school students enrolled in public charter schools in the U.S. Although charter schools were employed in this evaluation, these were affiliated with the larger public school district and served comparable student populations. Future research is needed to determine whether the effects of the SEI are replicable in other contexts.

\section{Conclusions}

This study provides evidence that the SEI improved students' sex- and sexuality- related knowledge, attitudes, communication, and self-efficacy immediately following curriculum delivery. As a part of the first largescale rigorous evaluation trial of a rights-based sexuality education intervention in the U.S., this study provides preliminary support to the theoretical foundations and potential for public health impact of this emerging intervention approach. Our results suggest that an intervention based on integrated theories of human rights, gender equality, and healthy sexual development can affect precursors to healthy sexual behavior among adolescents. Although much work is needed to understand the long-term effectiveness of the rights-based approach, the positive effects of the SEI on short-term psychosocial outcomes encourages further theoretical consideration, 
programmatic development, and empirical research to understand how this model could support and enhance adolescents' healthy sexual development.

\section{Abbreviations}

HIV: Human immunodeficiency virus; PPLA: Planned Parenthood Los Angeles; SEl: Sexuality Education Initiative; STI: Sexually transmitted infection.

\section{Competing interests}

The authors declare that they have no competing interests.

\section{Authors' contributions}

NAC served as principal investigator and LAR as co-principal investigator, and were responsible for the study's conceptualization and design. LAR and FAO supervised on-site data collection and quality control. PJ developed the analytic plan, conducted data cleaning and analyses, and oversaw the interpretation of the results, with statistical consultation from CPC and analytic support from NFB. NFB and PJ drafted the manuscript. NAC and LAR contributed to the writing and revising of the manuscript. All authors read and approved the final manuscript.

\section{Acknowledgements}

This study was funded by Planned Parenthood Los Angeles, with additional support from the Ford Foundation and the William and Flora Hewlett Foundation. The funders had no control over the analyses conducted, the results reported, or any other aspect of this article. We thank Gaylene Gunning for data collection management, Jennifer Tsai for analysis support, and the Planned Parenthood Los Angeles staff and leadership for following the rigorous study protocol.

\section{Author details}

${ }^{1}$ Center for Research on Adolescent Health and Development, Public Health Institute, 555 12th Street, 10th Floor, 94607 Oakland, CA, USA. ${ }^{2}$ Division of Community Health and Human Development, School of Public Health, University of California, Berkeley, 50 University Hall, 94720 Berkeley, CA, USA. ${ }^{3}$ Institute for Health Promotion and Disease Prevention Research, Keck School of Medicine, University of Southern California, 2001 N. Soto Street, 90032 Los Angeles, CA, USA.

Received: 12 December 2014 Accepted: 9 March 2015

Published online: 26 March 2015

\section{References}

1. Hamilton BE, Mathews TJ, Ventura SJ. Declines in State Teen Birth Rates by Race and Hispanic Origin. Hyattsville, MD: National Center for Health Statistics; 2013 [NCHS Data Brief].

2. Santelli J, Sandfort T, Orr M. Transnational comparisons of adolescent contraceptive use: What can we learn from these comparisons? Arch Pediatr Adolesc Med. 2008;162:92-4.

3. Kearney MS, Levine PB. Why is the teen birth rate in the United States so high and why does it matter? J Econ Perspect. 2012;26:141-66.

4. Kost K, Henshaw S. US Teenage Pregnancies, Births and Abortions, 2010: National and State Trends by Age, Race and Ethnicity. New York, NY: Guttmacher Institute; 2014.

5. Satterwhite $\mathrm{CL}$, Torrone E, Meites E, Dunne EF, Mahajan R, Ocfemia MCB, et al. Sexually transmitted infections among US women and men: Prevalence and incidence estimates, 2008. Sex Transm Dis. 2013:40:187-93.

6. Owusu-Edusei K, Chesson HW, Gift TL, Tao G, Mahajan R, Ocfemia MCB, et al. The estimated direct medical cost of selected sexually transmitted infections in the United States, 2008. Sex Transm Dis. 2013;40:197-201.

7. Martinez G, Abma J, Copen C. Educating Teenagers About Sex in the United States. Hyattsville, MD: National Center for Health Statistics; 2010 [NCHS Data Brief].

8. Kirby DB, Laris BA, Rolleri LA. Sex and HIV education programs: Their impact on sexual behaviors of young people throughout the world. J Adolesc Health. 2007;40:206-17.

9. Goesling B, Colman S, Trenholm C, Terzian M, Moore K. Programs to reduce teen pregnancy, sexually transmitted infections, and associated sexual risk behaviors: A systematic review. J Adolesc Health. 2014;54:499-507.

10. Chin HB, Sipe TA, Elder R, Mercer SL, Chattopadhyay SK, Jacob V, et al. The effectiveness of group-based comprehensive risk-reduction and abstinence education interventions to prevent or reduce the risk of adolescent pregnancy, Human Immunodeficiency Virus, and sexually transmitted infections. Am J Prev Med. 2012;42:272-94.

11. Kohler PK, Manhart LE, Lafferty WE. Abstinence-only and comprehensive sex education and the initiation of sexual activity and teen pregnancy. J Adolesc Health. 2008:42:344-51.

12. Goldfarb ES, Constantine NA. Sexuality education. In: Brown BB, Prinstein MJ, editors. Encycl Adolesc. San Diego, CA: Academic Press; 2011. p. 322-31.

13. Schalet AT. Beyond abstinence and risk: A new paradigm for adolescent sexual health. Womens Health Issues. 2011;21:S5-7.

14. Harden KP. A sex-positive framework for research on adolescent sexuality. Perspect Psychol Sci. 2014;9:455-69.

15. Halpern CT. Reframing research on adolescent sexuality: Healthy sexual development as part of the life course. Perspect Sex Reprod Health. 2010;42:6-7.

16. Berglas NF, Constantine NA, Ozer EJ. A rights-based approach to sexuality education: Conceptualization, clarification and challenges. Perspect Sex Reprod Health. 2014;46:63-72.

17. Hardee K, Kumar J, Newman K, Bakamjian L, Harris S, Rodríguez M, et al. Voluntary, human rights-based family planning: A conceptual framework. Stud Fam Plann. 2014;45:1-18.

18. Erdman JN, Cook RJ. Reproductive rights. In: Heggenhougen K, editor. Int Encycl Public Heal. Oxford: Academic; 2008.

19. Asian Communities for Reproductive Justice. A New Vision for Advancing Our Movement for Reproductive Health, Reproductive Rights and Reproductive Justice. Oakland, CA: Asian Communities for Reproductive Justice; 2005.

20. International Planned Parenthood Federation. IPPF Framework for Comprehensive Sexuality Education (CSE). London: International Planned Parenthood Federation; 2010.

21. WHO Regional Office for Europe \& BZgA. Standards for Sexuality Education in Europe: A Framework for Policy Makers, Educational and Health Authorities and Specialists. Cologne: Federal Centre for Health Education, BZgA; 2010.

22. United Nations Educational. Scientific and Cultural Organization: International Technical Guidance on Sexuality Education: An Evidenceinformed Approach for Schools, Teachers and Health Educators. Paris: UNESCO; 2009.

23. Advocates for Youth. The vision. Rights. Respect. Responsibility. Washington, DC: Advocates for Youth. [http://www.advocatesforyouth.org/the-3rs]

24. International Sexuality and HIV Curriculum Working Group. It's All One Curriculum: Guidelines and Activities for a Unified Approach to Sexuality, Gender, HIV, and Human Rights Education. New York, NY: Population Council; 2009

25. Rogow D, Haberland N, Del Valle A, Lee N, Osakue G, Sa Z, et al. Integrating gender and rights into sexuality education: field reports on using It's All One. Reprod Health Matters. 2013;21:154-66.

26. Rogow D, Haberland N. Sexuality and relationships education: toward a social studies approach. Sex Educ. 2005:5:333-44.

27. Marques M, Ressa N. The Sexuality Education Initiative: A programme involving teenagers, schools, parents and sexual health services in Los Angeles, CA, USA. Reprod Health Matters. 2013;21:124-35.

28. Pulerwitz J, Michaelis A, Verma R, Weiss E. Addressing gender dynamics and engaging men in HIV programs: lessons learned from Horizons research. Public Health Rep. 2010;125:282-92.

29. Crepaz N, Marshall KJ, Aupont LW, Jacobs ED, Mizuno Y, Kay LS, et al. The efficacy of HIV/STI behavioral interventions for African American females in the United States: A meta-analysis. Am J Public Health. 2009;99:2069-78.

30. DiClemente RJ, Wingood GM, Rose ES, Sales JM, Lang DL, Caliendo AM, et al. Efficacy of sexually transmitted disease/human immunodeficiency virus sexual risk-reduction intervention for African American adolescent females seeking sexual health services: A randomized controlled trial. Arch Pediatr Adolesc Med. 2009;163:1112-21.

31. Jewkes R, Nduna M, Levin J, Jama N, Dunkle K, Puren A, et al. Impact of Stepping Stones on incidence of HIV and HSV-2 and sexual behaviour in rural South Africa: cluster randomised controlled trial. BMJ. 2008;337:a506.

32. Wingood GM, DiClemente RJ, Mikhail I, Lang DL, McCree DH, Davies SL, et al. A randomized controlled trial to reduce HIV transmission risk behaviors and sexually transmitted diseases among women living with HIV. JAIDS. 2004;37:S58-67. 
33. Rijsdijk LE, Bos AE, Ruiter RA, Leerlooijer JN, de Haas B, Schaalma HP. The World Starts With Me: A multilevel evaluation of a comprehensive sex education programme targeting adolescents in Uganda. BMC Public Health. 2011;11:334.

34. Berglas NF, Angulo-Olaiz F, Jerman P, Desai M, Constantine NA. Engaging youth perspectives on sexual rights and gender equality in intimate relationships as a foundation for rights-based sexuality education. Sex Res Soc Policy. 2014;11:288-98.

35. Centerwall BS. Race, socioeconomic status, and domestic homicide. J Am Med Assoc. 1995;273:1755-8

36. Marin G, Sabogal F, Marin BV, Otero-Sabogal R, Perez-Stable EJ. Development of a short acculturation scale for Hispanics. Hisp J Behav Sci. 1987:9:183-205.

37. Norris AE, Ford K, Bova CA. Psychometrics of a brief acculturation scale for Hispanics in a probability sample of urban Hispanic adolescents and young adults. Hisp J Behav Sci. 1996;18:29-38.

38. McCoach DB, Adelson JL. Dealing with dependence (part I): Understanding the effects of clustered data. Gift Child Q. 2010;54:152-5.

39. McCoach DB. Dealing with dependence (part II): A gentle introduction to hierarchical linear modeling. Gift Child Q. 2010;54:252-6.

40. Murray DM, Hannan PJ. Planning for the appropriate analysis in schoolbased drug-use prevention studies. J Consult Clin Psychol. 1990;58:458-68.

41. Hedges LV, Hedberg EC. Intraclass correlation values for planning grouprandomized trials in education. Educ Eval Policy Anal. 2007;29:60-87.

42. Durlak JA. How to select, calculate, and interpret effect sizes. J Pediatr Psychol. 2009;34:917-28.

43. DiCenso A, Guyatt G, Willan A, Griffith L. Interventions to reduce unintended pregnancies among adolescents: systematic review of randomised controlled trials. BMJ. 2002;324:1426.

44. Scher LS, Maynard RA, Stagner M. Interventions intended to reduce pregnancy-related outcomes among adolescents. Campbell Syst Rev 2006;12.

45. Oringanje C, Meremikwu MM, Eko H, Esu E, Meremikwu A, Ehiri JE. Interventions for preventing unintended pregnancies among adolescents. Cochrane Database Syst Rev. 2009:4

46. DiClemente RJ, Wingood GM, Harrington KF, Lang DL, Davies SL, Hook EW et al. Efficacy of an HIV prevention intervention for African American adolescent girls: A randomized controlled trial. J Am Med Assoc 2004:292:171-9.

47. Davidson TM, Lopez CM, Saulson R, Borkman AL, Soltis K, Ruggiero KJ, et al. Development and preliminary evaluation of a behavioural HIV-prevention programme for teenage girls of Latino descent in the USA. Cult Health Sex. 2014;16:533-46.

48. Harrison A, O'Sullivan LF, Hoffman S, Dolezal C, Morrell R. Gender role and relationship norms among young adults in South Africa: Measuring the context of masculinity and HIV risk. J Urban Health. 2006:83:709-22.

49. Leech TGJ. Everything's better in moderation: Young women's gender role attitudes and risky sexual behavior. J Adolesc Health. 2010;46:437-43.

50. Wingood GM, DiClemente RJ. Application of the theory of gender and power to examine HIV-related exposures, risk factors, and effective interventions for women. Health Educ Behav. 2000;27:539-65.

51. Amaro H. Love, sex, and power. Considering women's realities in HIV prevention. Am Psychol. 1995;50:437-47.

52. Tolman DL, Striepe MI, Harmon T. Gender matters: Constructing a model of adolescent sexual health. J Sex Res. 2003:40:4-12

53. International Planned Parenthood Federation. Exploring New Territories: Dialogues from a Consultative Meeting on Comprehensive Sexuality Education. London: International Planned Parenthood Federation; 2012.

54. Beatty PC, Willis GB. Research synthesis: The practice of cognitive interviewing. Public Opin Q. 2007;71:287-311.

55. Siegel DM, Aten MJ, Roghmann KJ. Self-reported honesty among middle and high school students responding to a sexual behavior questionnaire. J Adolesc Health. 1998;23:20-8.

\section{Submit your next manuscript to BioMed Central and take full advantage of:}

- Convenient online submission

- Thorough peer review

- No space constraints or color figure charges

- Immediate publication on acceptance

- Inclusion in PubMed, CAS, Scopus and Google Scholar

- Research which is freely available for redistribution

Submit your manuscript at www.biomedcentral.com/submit 